\title{
Impact of Spatial Resolution on Simulated Consecutive Dry Days and Near-Surface Temperature over the Central Mountains in Japan
}

\author{
Shiori Sugimoto ${ }^{1}$, Rui Ito ${ }^{2}$, Koji Dairaku ${ }^{3}$, Hiroaki Kawase ${ }^{4}$, Hidetaka Sasaki ${ }^{4}$, Shingo Watanabe ${ }^{1}$, \\ Yasuko Okada ${ }^{1}$, Sho Kawazoe ${ }^{1}$, Takeshi Yamazaki ${ }^{5}$, and Takahiro Sasai ${ }^{5}$ \\ ${ }^{1}$ Japan Agency for Marine-Earth Science and Technology (JAMSTEC), Yokohama, Japan \\ ${ }^{2}$ Japan Meteorological Business Support Center, Tsukuba, Japan \\ ${ }^{3}$ National Research Institute for Earth Science and Disaster Resilience (NIED), Tsukuba, Japan \\ ${ }^{4}$ Meteorological Research Institute (MRI), Japan Meteorological Agency, Tsukuba, Japan \\ ${ }^{5}$ Tohoku University, Sendai, Japan
}

\begin{abstract}
To evaluate the influence of spatial resolution in numerical simulations on the duration of consecutive dry days (CDDs) and near-surface temperature over the central mountains in Japan, a regional climate model was used to conduct two experiments with horizontal resolutions of 5 and $20 \mathrm{~km}$. Compared with observations, the spatial and temporal features of the CDDs were simulated well in the $5 \mathrm{~km}$ experiment, whereas in the $20 \mathrm{~km}$ simulation they were overestimated over the mountains and underestimated in the surrounding regions. The accuracy in the simulated CDDs affected the near-surface temperature in the model. In years with a difference of more than five days in the CDDs between the 5 and $20 \mathrm{~km}$ experiments, near-surface temperatures over the mountains were $0.2-0.3 \mathrm{~K}$ lower in the $5 \mathrm{~km}$ simulation compared with the $20 \mathrm{~km}$ simulation. This was due to the lower number of CDDs in $5 \mathrm{~km}$ simulation causing active cloud convection and reduced net radiation at the ground, resulting from a large decrease in the solar radiation at the ground. In addition, a land surface wetness controls a spatial heterogeneity of temperature difference between two experiments.
\end{abstract}

(Citation: Sugimoto, S., R. Ito, K. Dairaku, H. Kawase, H. Sasaki, S. Watanabe, Y. Okada, S. Kawazoe, T. Yamazaki, and T. Sasai, 2018: Impact of spatial resolution on simulated consecutive dry days and near-surface temperature over the central mountains in Japan. SOLA, 14, 46-51, doi:10.2151/sola.2018-008.)

\section{Introduction}

Increasing the spatial resolution of numerical simulations results in marked performance improvement in simulating regionaland local-scale precipitation, particularly in mountainous regions (Sato et al. 2008; Hara et al. 2009; Takahashi et al. 2010; Sasaki et al. 2011; Langhans et al. 2013; Fosser et al. 2015; Sugimoto and Takahashi 2016; Dado and Takahashi 2017). Cloud convections in numerical simulations control the solar radiation and downward longwave radiation at the ground, which modifies the simulated near-surface temperature (Langhans et al. 2013; Fosser et al. 2015). Precipitation also alters the land surface wetness and Bowen ratio, which subsequently affects heating processes in the near-surface layer (e.g. Seneviratne et al. 2010). Since Japan has complex topography, the influence of spatial resolution in numerical simulations on the local-scale precipitation and its effect on near-surface temperature need to be assessed.

The maximum duration of consecutive dry days (CDDs) in a year (i.e., consecutive days when the precipitation is $<1.0$ $\mathrm{mm}$ day $^{-1}$ ) is commonly used to capture the length of an extreme dry event (Fritch et al. 2002). Prolonged periods with minimal pre-

Corresponding author: Shiori Sugimoto, Japan Agency for Marine-Earth Science and Technology, 3173-25, Showa-machi, Kanazawa-ku, Yokohama 236-0001, Japan. E-mail: shiorisug@jamstec.go.jp. cipitation can adversely affect human activity, including reduced water resources and an increase in the number of extremely hot days. An increasing trend in dry weather has been observed over the majority of Japan in the past climate between 1901 and 2004 (Fujibe et al. 2006). Although this trend has not been reproduced in atmospheric general circulation model (AGCM) simulations with coarse spatial resolution (Kiktev et al. 2003; Mizuta et al. 2005), a dynamically downscaled simulation with $5 \mathrm{~km}$ horizontal resolution, using input data from a regional objective analysis, showed good agreement with the observations of CDDs during the warm season (Nakano et al. 2011). These results suggest that numerical experiments with a higher spatial resolution are able to simulate CDDs because of the improvement of simulated precipitation, even acknowledging that the numerical setup and initial and boundary conditions differ between experiments.

In the present study, numerical simulations with horizontal resolutions of 5 and $20 \mathrm{~km}$ were conducted over Japan using a regional climate model. The numerical setup for 5 and $20 \mathrm{~km}$ experiments are almost same as shown in Section 2 to assess whether a higher spatial resolution results in improved accuracy of the simulations. In addition, years with the largest differences between the CDDs from the two experiments were identified, and the impact of the simulated CDDs on near-surface temperature, in relation to radiative and surface heating processes, was discussed.

\section{Numerical setup and data}

To examine the accuracy of the simulated CDDs and their impact on near-surface temperature, two separate numerical experiments with different spatial resolutions were conducted using a nonhydrostatic regional climate model (NHRCM) developed by the Meteorological Research Institute/Japan Meteorological Agency (MRI/JMA) (Sasaki et al. 2008). The horizontal resolutions were 5 and $20 \mathrm{~km}$, with 50 and 40 vertical layers, respectively (hereafter, $5 \mathrm{~km}$ run and $20 \mathrm{~km}$ _run; Fig. 1). The $20 \mathrm{~km}$ run simulation covered the period from 0000 UTC July 1 each year to 0000 UTC September 16 of the following year during 1980-2011 (i.e., 31 years). The $5 \mathrm{~km}$ run simulation covered a shorter period from 0000 UTC July 24 each year to 0000 UTC September 1 of the following year, again during 1980-2011. Here, we only analyze each August in the following year (during 1981-2011) to allow for the spin-up in soil moisture content and to minimize the impact of synoptic disturbances on precipitation processes in Japan.

The physics schemes used in the experiments are similar to those for $20 \mathrm{~km}$ run of Kawase et al. (2016) and Mizuta et al. (2017), and include a clear-sky radiation scheme (Yabu et al. 2005), a cloud radiation scheme (Kitagawa et al. 2000), a bulktype cloud microphysics scheme (Ikawa et al. 1991), the Kain Fritsch convective parameterization (Kain and Fritsch 1993), the Mellor-Yamada-Nakanishi-Niino Level 3 turbulence kinetic energy scheme for planetary boundary layer conditions (Nakanishi and Niino 2004), and the improved MRI/JMA simple biosphere 
(a)

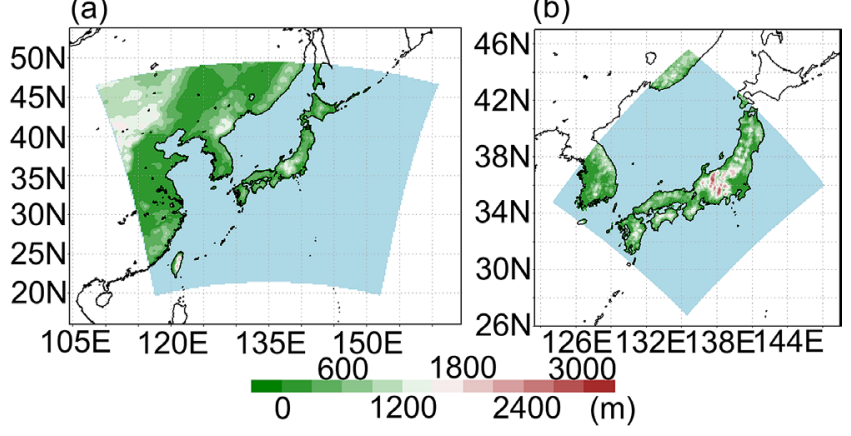

Fig. 1. Topography in the experiment domains for (a) $20 \mathrm{~km}$ run and (b) $5 \mathrm{~km}$ run without sponge layers (10 grids for each boundary). Light blue areas denote water.

model (iSiB) with three (four) layers for soil moisture (soil temperature) calculation based on Sellers et al. (1986), Sato et al. (1989), Hirai and Oh'izumi (2004), and Hirai et al. (2007). The shortwave and longwave radiations are calculated every 900 seconds (i.e., 15 minutes) for $5 \mathrm{~km}$ run and $20 \mathrm{~km}$ run. The Kain Fritsch convective parameterization is adopted for both experiments. The urban category is only considered in $5 \mathrm{~km}$ run, for which the square prime urban canopy scheme (SPUC; Aoyagi and Seino 2011) is adopted. The use of SPUC only in the $5 \mathrm{~km}$ run does not seriously affect the analysis of this study although several urban grids scatter in the mountainous regions (not shown).

Initial and boundary conditions for the atmosphere and land surface are from the Japanese 55-year Reanalysis (JRA-55; Kobayashi et al. 2015; Harada et al. 2016) for 20km run, and from the output of $20 \mathrm{~km}$ run for $5 \mathrm{~km}$ run (i.e., one-way nesting). The index for CDDs is defined as the maximum duration of consecutive days with precipitation less than $1.0 \mathrm{~mm} \mathrm{day}^{-1}$ in August of each year. Since the output interval of both numerical experiments was hourly, the output was accumulated over 24 hours between 0000 and 2400 local time (LT) to obtain the daily precipitation. Monthly averages of the daily mean temperature at $1.5 \mathrm{~m}$ from the ground $\left(\mathrm{T}_{\mathrm{sa}}\right.$ ), cloud cover (from 0 to 1 ), solar radiation, upward shortwave radiation, upward/downward longwave radi- ation, and sensible and latent heat fluxes at the ground were also calculated for each experiment to diagnose the physical processes responsible for differences in the simulated $\mathrm{T}_{\mathrm{sa}}$ between the two experiments. Note that an elevation correction is applied to $\mathrm{T}_{\mathrm{sa}}$ before the analysis. To validate the simulated CDDs, the daily precipitation from Asian Precipitation - Highly-Resolved Observational Data Integration Towards Evaluation of water resources (APHRODITE, horizontal resolution of $0.05^{\circ} \times 0.05^{\circ}$; Kamiguchi et al. 2010; Yatagai et al. 2012) was obtained. The monthly mean precipitation was also calculated to compare differences in the accuracy of the simulated CDDs.

\section{Comparison of simulated CDDs accuracy between the 5 and $20 \mathrm{~km}$ experiments}

Figure S1 shows the spatial distribution of the CDDs in August over Japan. In the observations, the CDDs over mountainous regions are shorter than those over the plains, which suggests frequent orographic precipitation in August. The spatial heterogeneity of the CDDs is generally reproduced in $5 \mathrm{~km}$ run; however, $20 \mathrm{~km}$ run overestimates the CDDs over mountainous regions, particularly the central mountains of Japan, and underestimates the CDDs over regions surrounding the mountains (Figs. $2 \mathrm{a}, 2 \mathrm{~b}$, and $2 \mathrm{c}$ ). Realistic complex mountain-valley topography in central Japan is featured in $5 \mathrm{~km}$ run that is not resolved in $20 \mathrm{~km}$ run. Since precipitation tends to occur over the mountain slopes in both experiments, the smoother topography over the inland mountainous region in $20 \mathrm{~km}$ run compared with $5 \mathrm{~km}$ run leads to the overestimation of $\mathrm{CDDS}^{-}$(i.e., the frequency of precipitation is underestimated; Fig. 2c). The CDDs averaged over the mountainous area in central Japan (black rectangles in Figs. 2a, 2b, and 2c) are evaluated for each year (Fig. 3). The interannual variability in CDDs for $5 \mathrm{~km}$ run is in good agreement with observations, with a root mean square error (RMSE) of 1.53 and a correlation coefficient (CC) of 0.84 . However, $20 \mathrm{~km}$ run consistently overestimates CDDs, resulting in a RMSE of $4 . \overline{2} 4$ and a CC of 0.52 .

On the other hand, the spatial distribution of the observed monthly mean precipitation is accurately simulated in both experiments unlike the CDDs (Figs. 2d, 2e, and 2f). The interannual variability was also well captured with a RSME of 2.94 and 2.76 , and a CC of 0.60 and 0.67 , for $20 \mathrm{~km} \_$run and $5 \mathrm{~km} \_$run,

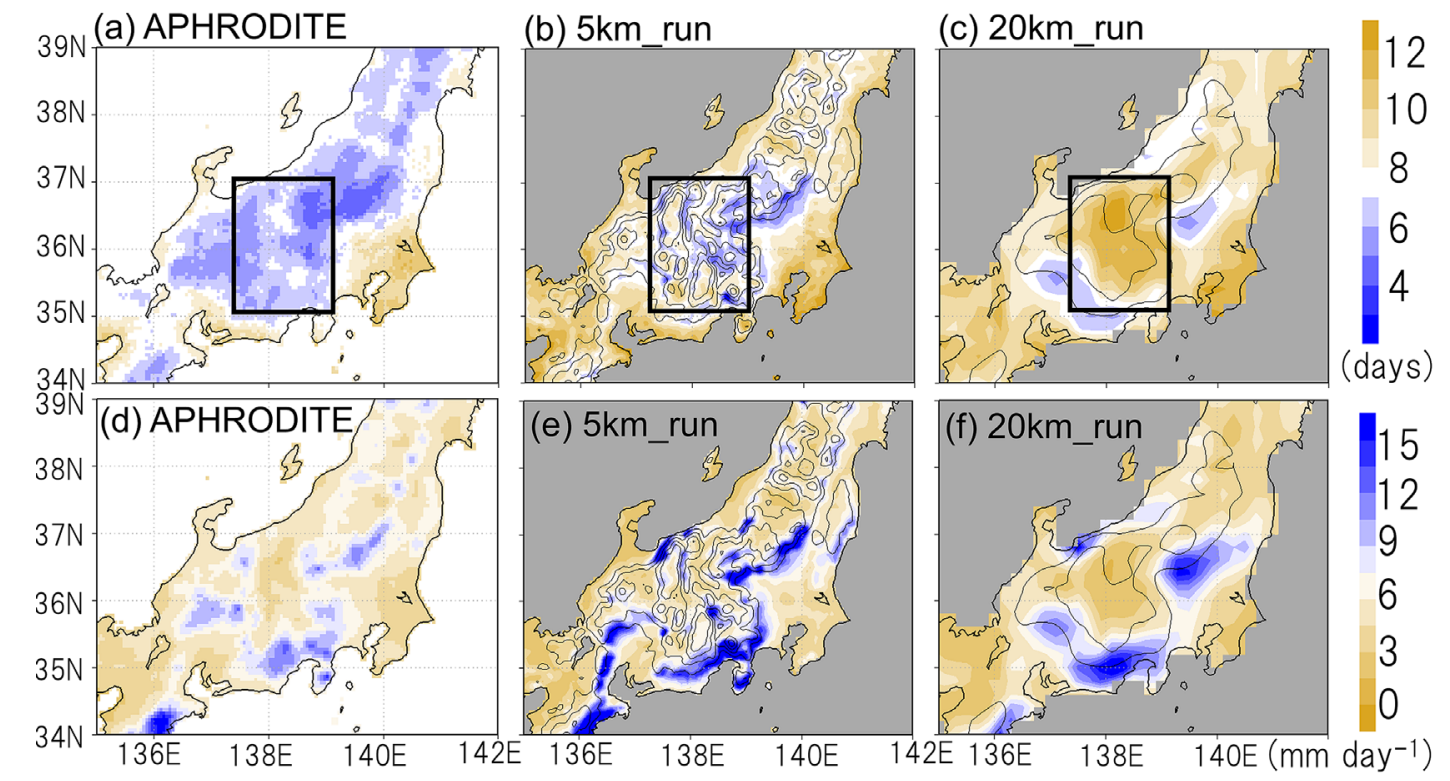

Fig. 2. The 31-year mean of CDDs in August for (a) observations (APHRODITE), (b) $5 \mathrm{~km}$ run, and (c) $20 \mathrm{~km}$ run over the central mountains in Japan. Also shown is the 31-year climatology of monthly mean precipitation over the central mountains during August for (d) observations (APHRODITE), (e) $5 \mathrm{~km}$ run, and (f) $20 \mathrm{~km}$ run. The topographic contour interval in (b), (c), (e), and (f) is $500 \mathrm{~m}$ above sea level (a.s.1.). Gray shading indicates water body. Rectangles indicate the region of the area-averaged consecutive dry days shown in Fig. 3. 
(a)

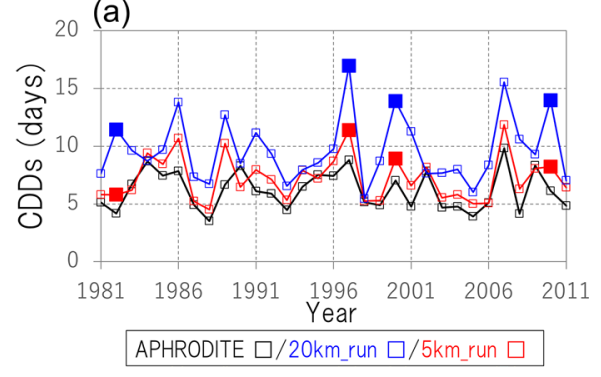

(b)

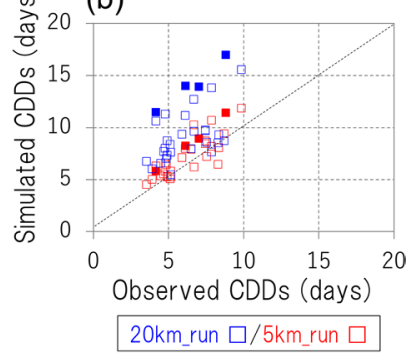

Fig. 3. (a) Interannual variability in area-averaged consecutive dry days over the central mountains in Japan during August. (b) The relationship between consecutive dry days from the observations and simulations. Filled marks in Fig. (a) and (b) indicate four years with a difference in the CDDs between the two experiments of more than five days.

respectively (not shown). Therefore, we suggest that, while $5 \mathrm{~km}$ run is more suitable for evaluating the precipitation occurrence at daily timescales, $20 \mathrm{~km} \_$run is equally suitable for evaluating the precipitation amount at monthly timescales.

The CDDs difference between two experiments implies the difference of precipitation frequency. Indeed, the precipitation frequently occurs over the central mountains of Japan in $5 \mathrm{~km}$ run relative to that in $20 \mathrm{~km}$ run (not shown). To certainly discuss the influence of CDDs on radiative and land-surface processes, we need analyze and understand the difference in occurrence frequency of cloudy days, which is defined as the day with cloud cover more than 0.8 and precipitation $<1.0 \mathrm{~mm} \mathrm{day}^{-1}$ (i.e., including non-precipitation days), between two experiments. Few cloudy days are detected for both of $5 \mathrm{~km}$ run and $20 \mathrm{~km}$ run (Figs. S2a and $\mathrm{S} 2 \mathrm{~b}$ ), and a difference between them is quite small relative to that in the CDDs and precipitation frequency (Fig. S3a). The occurrence frequency of the day with cloud cover between 0.3 and 0.8 and precipitation $<1.0 \mathrm{~mm} \mathrm{day}^{-1}$ is also examined, which is lower over the mountainous regions in $5 \mathrm{~km}$ run than $20 \mathrm{~km}$ run (Figs. S2c, S2d, and S3b). This result indicates that the overestimated CDDs in $20 \mathrm{~km}$ run does not lead to a decrease of the day with cloud and less precipitation over the mountains, and the simulation accuracy of the CDDs would correspond to that in the clouds with precipitation.

\section{Influence of CDDs model performance on $\mathbf{T}_{\mathrm{sa}}$}

Large CDDs values indicate periods with no or few precipitation, while small CDDs values indicate a frequent occurrence of precipitation. As discussed in Section 1, cloud convection associated with precipitation is the primary control on radiative processes, and precipitation modifies land surface wetness and the partitioning between latent and sensible heat fluxes. Therefore, accuracy in the simulated CDDs will affect the simulated $\mathrm{T}_{\mathrm{sa}}$ through changes in radiative and land surface processes. In this section, the impact of the simulated CDDs on $\mathrm{T}_{\mathrm{sa}}$ is examined using the model output, and the related physical mechanisms are discussed. Note that $T_{\mathrm{sa}}$ is estimated via an interpolation between skin temperature and atmospheric temperature at bottom layer in the model. The skin temperature with different topography cannot be modified only by the elevation correction since it differs with the atmospheric temperature. When the $\mathrm{T}_{\mathrm{sa}}$ is strongly affected by the skin temperature, the elevation correction would be insufficient to eliminate biases in $\mathrm{T}_{\mathrm{sa}}$ between $5 \mathrm{~km}$ run and $20 \mathrm{~km}$ run. Therefore, we first identified four years with a difference in the CDDs between the two experiments of more than five days, that is 1982, 1997, 2000, and 2010. Second, the $\mathrm{T}_{\mathrm{sa}}$ anomalies, defined as the difference between the four years composite and climatology, were calculated for each experiment after the interpolation from 5 $\mathrm{km}$ to 0.05 -degree resolution for $5 \mathrm{~km}$ run and from $20 \mathrm{~km}$ to $0.2-$ degree resolution for $20 \mathrm{~km}$ _run (Figs. $4 \mathrm{a}$ and $4 \mathrm{~b}$ ). Lastly, the $\mathrm{T}_{\mathrm{sa}}$ anomaly with 0.05 -degree resolution in $5 \mathrm{~km}$ run is converted to 0.2 -degree resolution by box averaging, and the difference in the $\mathrm{T}_{\mathrm{sa}}$ anomaly between $5 \mathrm{~km}$ _run and $20 \mathrm{~km}$ run was calculated (Fig. $4 \mathrm{c})$. This calculation highlights the $\mathrm{T}_{\mathrm{sa}}$ difference between the two experiments over the central mountainous region caused by the radiative and heating processes at the ground.

Figure $4 \mathrm{c}$ shows that the daily mean $\mathrm{T}_{\mathrm{sa}}$ is $0.2-0.3 \mathrm{~K}$ lower in $5 \mathrm{~km}$ run than in $20 \mathrm{~km} \_$run over the central mountains, which is associated with the lower CDDs (Fig. 5a). The lower CDDs in $5 \mathrm{~km}$ _un compared with $20 \mathrm{~km}$ _run are accompanied by a decrease in net radiation, driven mainly by a reduction in solar radiation at the ground (Figs. 6a and 6b), despite the use of same radiation schemes between two experiments. Sensible and latent heat fluxes decrease over the mountains due to the change in net radiation (Figs. $6 \mathrm{c}$ and $6 \mathrm{~d}$ ). Focucing on the central mountainous regions, a decrease in wind speed, which would be caused by an increase in roughness of topography, also tends to influence on the decrease in surface heat fluxes (Fig. S4). Consequently, the $\mathrm{T}_{\mathrm{sa}}$
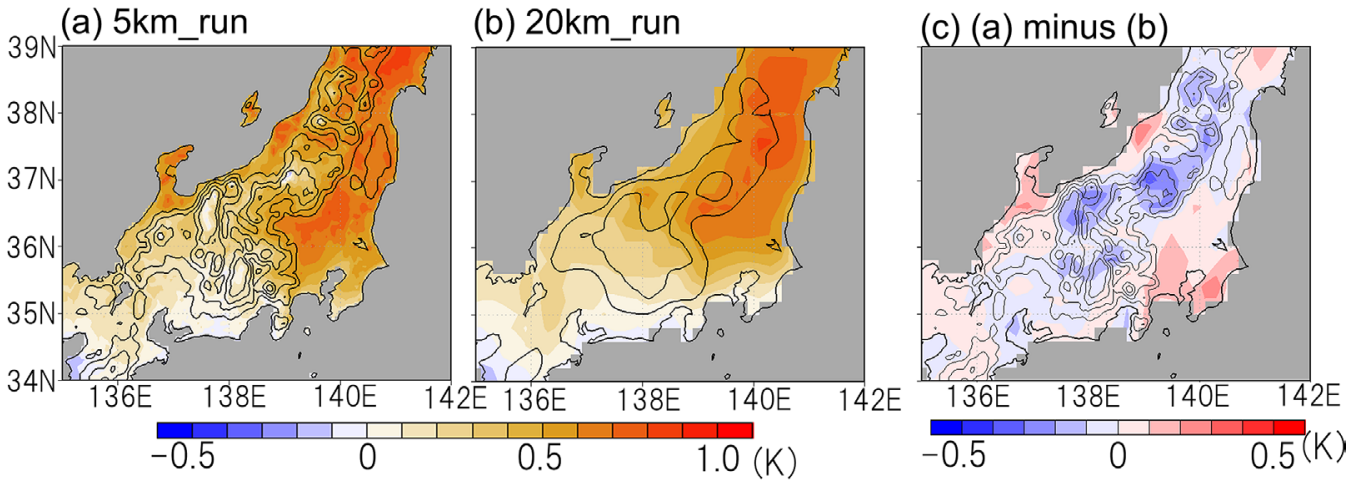

Fig. 4. Near-surface temperature $\left(\mathrm{T}_{\mathrm{sa}}\right)$ anomalies between the composite of four selected years and the climatology for (a) $5 \mathrm{~km} \_$run and (b) 20km_run. (c) Difference between (a) and (b). The topographic contour interval in $(\mathrm{a}-\mathrm{c})$ is $500 \mathrm{~m}$ a.s.l., using the dataset of $5 \mathrm{~km} \_$run for (a) and (c), and that of $20 \mathrm{~km}$-run for (b). Gray shading indicates water body. 
(a) CDDs

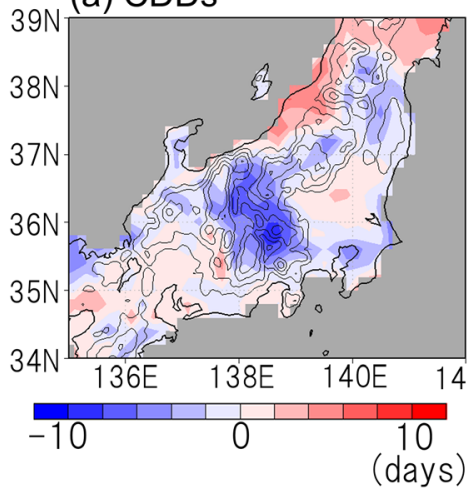

(b) Monthly precipitation

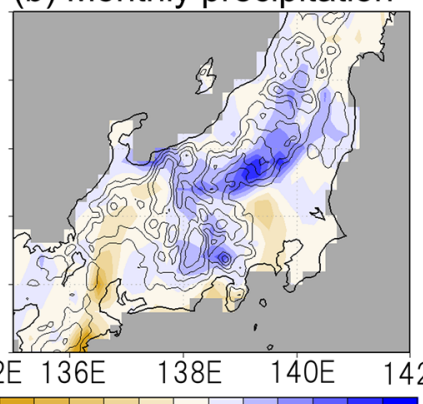

(c) Soil moisture wetness

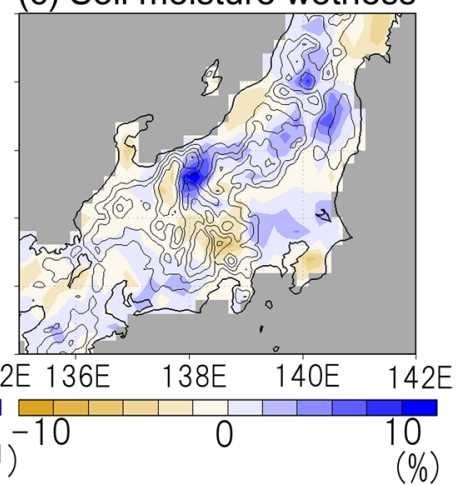

Fig. 5. As for Fig. 4c, but for (a) CDDs, (b) monthly mean precipitation, and (c) soil moisture wetness.

(a) Net rad.

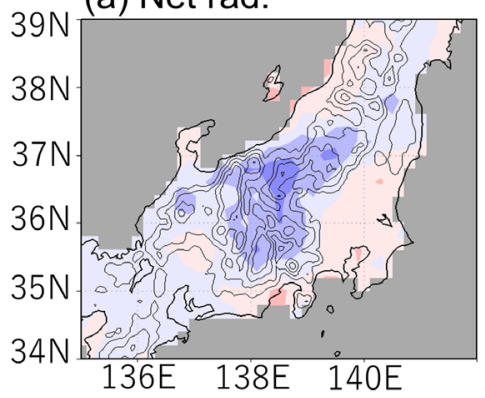

(e) Up Longwave rad.

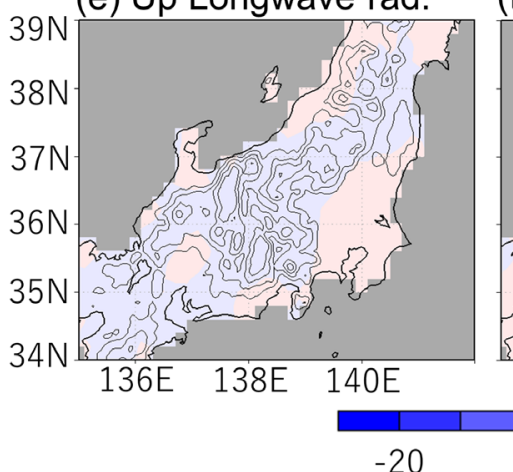

(b) Solar rad.

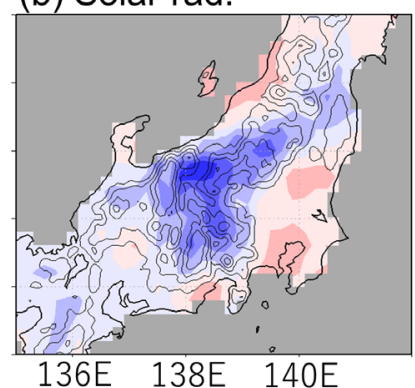

(c) Sensible H Flux

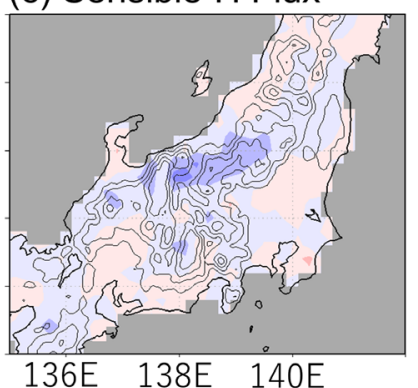

(d) Latent H Flux

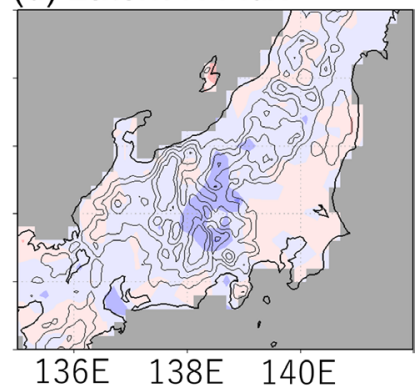

(f) Down Longwave rad.
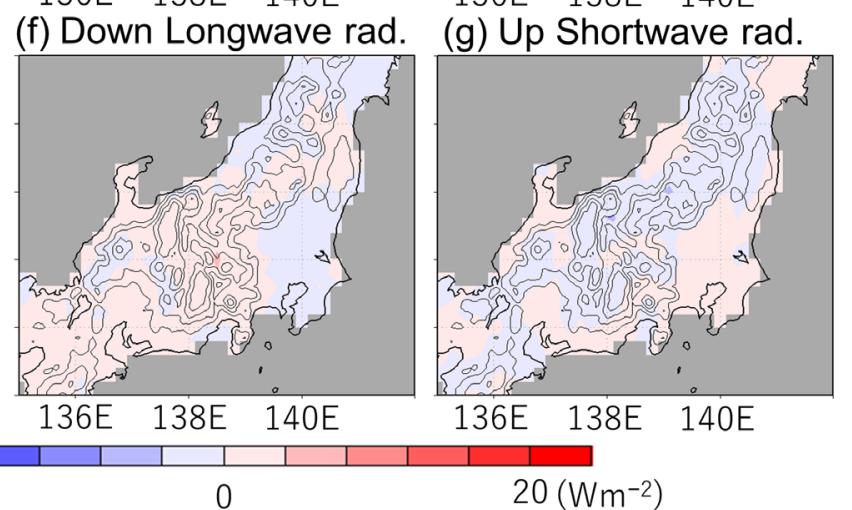

Fig. 6. As for Fig. 4c, but for (a) net radiation, (b) solar radiation, (c) sensible heat flux, (d) latent heat flux, (e) upward longwave radiation, (f) downward longwave radiation, and $(\mathrm{g})$ upward shortwave radiation at the ground.

is lower over the mountains in $5 \mathrm{~km}$ run than in $20 \mathrm{~km}$ run. The upward/downward longwave radiation and upward shortwave radiation at the surface have negligible influence on temperature in this case (Figs. 6e, 6f, and 6g). We suggest that a spatial heterogeneity in the $\mathrm{T}_{\mathrm{sa}}$ differences between two experiments is controlled by a soil moisture wetness (the percentage of volumetric soil moisture in the layer to its value at saturation). The entire soil layer is wetter (drier) over the northern (southern) part of the central mountains of Japan in $5 \mathrm{~km}$ run than $20 \mathrm{~km}$ run (Fig. $5 \mathrm{c}$, only for the 1st layer). However, this is dependent not only on precipitation amounts in August (Fig. 5b) but for the preceding months as well. In $5 \mathrm{~km}$ run, the wetter land-surface condition enhances the reduction of sensible heat flux over the northern part (Fig. 6c), and it causes the large modification of $\mathrm{T}_{\mathrm{sa}}$ relative to that over the southern part as shown in Fig. 4c.

\section{Conclusions and discussion}

Numerical experiments with 5 and $20 \mathrm{~km}$ horizontal resolutions were conducted to evaluate the effect of resolution on the simulated local-scale precipitation, with a particular focus over mountainous regions in central Japan. The index of CDDs was calculated using the output from both experiments and compared with observations. In $20 \mathrm{~km}$ _run, the CDDs was overestimated and underestimated over the mountains and plains surrounding the mountains, respectively, when compared to the observations and $5 \mathrm{~km}$ _run. Since precipitation occurred mainly over the mountain slopes in the numerical simulations irrespective of the spatial resolution, the representation of the complex topography in Japan played an important role in accurately simulating realistic CDDs. The accuracy of the simulated CDDs modified $\mathrm{T}_{\mathrm{sa}}$ in the model through radiative and land-surface processes. In years with large differences in CDDs between $5 \mathrm{~km}$ run and $20 \mathrm{~km}$ run, monthly averages of daily mean net radiation were lower in $5 \mathrm{~km}$ run 
than in $20 \mathrm{~km}$ run because cloud convections with precipitation reduced solar radiation at the ground. The sensible and latent heat fluxes also decreased, resulting in monthly averages of daily mean $\mathrm{T}_{\mathrm{sa}}$ that were $0.2-0.3 \mathrm{~K}$ lower in $5 \mathrm{~km}$ run than $20 \mathrm{~km}$ run over the central mountains. The spatial heterogeneity in the $\overline{\mathrm{T}}_{\mathrm{sa}}$ difference depended on the difference in the soil moisture wetness between two experiments.

With the exception of 1982, sea level pressure was higher over the central mountainous region than the climatology, which would be associated with slightly higher $\mathrm{T}_{\mathrm{sa}}$ as shown in Figs. $4 \mathrm{a}$ and $4 \mathrm{~b}$. This weather condition implies infrequent precipitation events under a development of the Northwestern Pacific High in those years. Indeed, the CDDs tends to be large except for 1982. However, it is difficult to statistically discuss a characteristic of weather condition when the CDDs overestimates in the simulation with coarse spatial resolution, because the synoptic circulation pattern is not always consistent among the four detected years (not shown). Large ensemble datasets from the RCM may provide more clarity on this issue, but is outside the scope of this study.

The dynamically downscaled dataset of radiation and $\mathrm{T}_{\mathrm{sa}}$ can be utilized to evaluate possible influences of climate change on local-scale human activities such as agriculture and in causing a warmer environment. For example, the differences in monthly averaged daily mean $\mathrm{T}_{\mathrm{sa}}$ of $0.2-0.3 \mathrm{~K}$ are significant when considering local-scale temperature changes and the effects on human activity in the near future. Since a spatial distribution of the agricultural land over the mountainous regions is deeply related with that of solar radiation at the ground (e.g. Kurose 1991), the difference in monthly averaged daily mean net and solar radiations between the two experiments of $\sim 10 \mathrm{~W} \mathrm{~m}^{-2}$ (Fig. 6a) may also have a large influence on the estimation of agricultural production using results from regional climate models. Therefore, there is added value in the use of high-resolution simulations to assess the possible impacts of local-scale climate change on human society.

The representation of mountain topography was key issue in accurately simulating the CDDs. Generally, numerical simulations with spatial resolution less than $4 \mathrm{~km}$ are capable of resolving cloud convection (e.g. Prein et al. 2015). Although $5 \mathrm{~km}$ run could be considered somewhat coarse for a convection-permitting simulation, the difference in spatial resolution between the two experiments may also affect the simulation of cloud convection. Additional numerical experiments, such as a simulation using high spatial resolution with coarse topography, could help to elucidate the individual impacts of topography representation and cloud resolving on the simulated precipitation.

\section{Acknowledgements}

We thank Dr. Mikiko Fujita of the JAMSTEC, Dr. Mitsuo Oh'izumi of the Meteorological College/JMA, and Dr. Noriko N. Ishizaki of the NIED for helpful discussions and technical supports. This work was supported by the Social Implementation Program on Climate Change Adaptation Technology (SI-CAT) of the Ministry of Education, Culture, Sports, Science and Technology (MEXT), Japan. We used disaster prevention information systems at NIED to conduct the simulations. The dataset used in this study is from the JRA-55 project carried out by the JMA (http:// jra.kishou.go.jp/JRA-55/index en.html) and the APHRODITE project (http://www.chikyu.ac.jp/precip/index.html).

Edited by: H. Fudeyasu

\section{Supplement}

Supplementary figure 1 (Fig. S1) is the same as Fig. 2 but for over Japan. Occurrence frequency of the days with clouds when daily precipitation $<1.0 \mathrm{~mm}$ is shown in supplementary figure 2 (Fig. S2), and its difference between two experiments is in supplementary figure 3 (Fig. S3). Supplementary figure 4 (Fig. S4) is the same as Fig. 4c but for wind speed.

\section{References}

Aoyagi, T., and N. Seino, 2011: A square prism urban canopy scheme for the NHM and its evaluation on summer conditions in the Tokyo metropolitan area, Japan. J. Appl. Meteor. Climatol., 50, 1476-1496.

Dado, J. M., and H. G. Takahashi, 2017: Effect of spatial resolution on simulated rainfall over western Philippines. Geographical Reports of Tokyo Metropolitan University, 52, 1-9.

Fosser, G., S. Khodayar, and P. Berg, 2015: Benefit of convection permitting climate model simulations in the representation of convective precipitation. Climate Dyn., 44, 45-60.

Frich, P., L. V. Alexander, P. Della-Marta, B. Gleason, M. Haylock, A. M. G. Klein Tank, and T. Peterson, 2002. Observed coherent changes in climatic extremes during the second half of the twentieth century. Climate Res., 19, 193-212, doi:10.3354/cr019193.

Fujibe, F., N. Yamazaki, and K. Kobayashi, 2006: Long-term changes of heavy precipitation and dry weather in Japan (1901-2004). J. Meteor. Soc. Japan, 84, 1033-1046.

Hara, M., T. Yoshikane, H. G. Takahashi, F. Kimura, A. Noda, and T. Tokioka, 2009: Assessment of the diurnal cycle of precipitation over the maritime continent simulated by a $20 \mathrm{~km}$ mesh GCM using TRMM PR data. J. Meteor. Soc. Japan, 87A, 413-424.

Harada, Y., H. Kamahori, C. Kobayashi, H. Endo, S. Kobayashi, Y. Ota, H. Onoda, K. Onogi, K. Miyaoka, and K. Takahashi, 2016: The JRA-55 Reanalysis: Representation of atmospheric circulation and climate variability. J. Meteor. Soc. Japan, 94, 269-302.

Hirai, M., and M. Oh'izumi, 2004: Development of a new land-surface model for JMA-GSM, Extended abstract of 20th Conf. Wea. Anal. Forecasting/16th Conf. NWP, p2.22 (Available online at https://ams.confex.com/ams/84Annual/ techprogram/paper_68652.htm, accessed 25 December 2017).

Hirai, M., T. Sakashita, H. Kitagawa, T. Tsuyuki, M. Hosaka, and M. Oh'izumi, 2007: Development and validation of a new land surface model for JMA's operational global model using the CEOP observation dataset. J. Meteor. Soc. Japan, $\mathbf{8 5 A}, 1-24$.

Ikawa M., H. Mizuno, T. Matsuo, and co-authors, 1991: Numerical modeling of the convective snow cloud over the Sea of Japan-Precipitation mechanism and sensitivity to ice crystal nucleation rates. J. Meteor. Soc. Japan, 69, 641-667.

Kain, J. S, and Fritsch J.M., 1993: Convective parameterization for mesoscale models: The Kain-Fritsch scheme. The Representation of Cumulus Convection in Numerical Models, Emanuel KA and Raymond DJ, Eds, pp. 165-170, Am. Meteorol. Soc., Boston, US, 165-170.

Kamiguchi, K., O. Arakawa, A. Kitoh, A. Yatagai, A. Hamada, and N. Yasutomi, 2010; Development of APHRO_JP, the first Japanese high-resolution daily precipitation product for more than 100 years. Hydrol. Res. Lett., 4, 60-64, doi: 10.3178/HRL.4.60.

Kawase, H., A. Murata, R. Mizuta, H. Sasaki, M. Nosaka, M. Ishii, and I. Takayabu, 2016: Enhancement of heavy daily snowfall in central Japan due to global warming as projected by large ensemble of regional climate simulations. Climatic Change, 139, 265-278, doi:10.1007/s10584-0161781-3.

Kiktev, D., D. M. H. Sexton, L. Alexander, and C. K. Folland, 2003: Comparison of modeled and observed trends in indices of daily climate extremes. J. Climate, 16, 3560-3571.

Kitagawa, H., 2000: Radiation processes. Separate volume of annual report of NPD, 46, 16-31 (in Japanese).

Kobayashi, S., Y. Ota, Y. Harada, A. Ebita, M. Moriya, H. Onoda, K. Onogi, H. Kamahori, C. Kobayashi, H. Endo, K. Miyaoka, and K. Takahashi, 2015: The JRA-55 Reanalysis: General specifications and basic characteristics. J. Meteor. 
Soc. Japan, 93, 5-48.

Kurose, Y., 1991: Estimation model for spatial distribution of solar radiation over complex terrains using $250-\mathrm{m}$ grid size data. J. Agr. Met., 47, 95-99. (in Japanese with English abstract)

Langhans, W., J. Schmidli, O. Fuhrer, S. Bieri, and C. Schar, 2013: Long-term simulations of thermally driven flows and orographic convection at convection-parameterizing and cloud resolving resolutions. J. Appl. Meteor. Climatol., 52, 1490-1510.

Mizuta, R., A. Murata, M. Ishi, and co-authors, 2017: Over 5000 years of ensemble future climate simulations by $60 \mathrm{~km}$ global and $20 \mathrm{~km}$ regional atmospheric models. Bull. Amer. Meteor. Soc., 98, 1383-1398, doi:10.1175/BAMS-D-160099.1.

Mizuta, R., T. Uchiyama, K. Kamiguchi, A. Kitoh, and A. Noda, 2005: Changes in extremes indices over japan due to global warming projected by global $20-\mathrm{km}$-mesh atmospheric model. SOLA, 1, 153-156, doi:10.2151/sola.2005-040.

Nakanishi, M., and H. Niino, 2004: An improved Mellor-Yamada level-3 model: its design and verification. Bound.-Layer Meteor., 112, 1-31.

Nakano, M., S. Kanada, T. Kato, and K. Kurihara, 2011: Monthly maximum number of consecutive dry days in Japan and its reproducibility by a $5-\mathrm{km}-\mathrm{mesh}$ cloud-system resolving regional climate model. Hydrol. Res. Lett., 5, 11-15, doi: 10.3178/HRL.5.11.

Prein, F. A., and co-authors, 2015: A review on regional convection-permitting climate modeling demonstrations, prospects, and challenges. Rev. Geophys., 53, 323-361, doi:10.1002/ 2014RG000475.

Sasaki, H., A. Murata, M. Hanafusa, M. Oh'izumi, and K. Kurihara, 2011: Reproducibility of present climate in a NonHydrostatic Regional Climate Model nested within an atmosphere General Circulation Model. SOLA, 7, 173-176.

Sato, N., P. J. Sellers, D. A. Randall, E. K. Schneider, J. Shukla,
J. L. Kinter III, Y.-T. Hou, and E. Albertazzi, 1989: Effect of implementing the simple biosphere model in a general circulation model. J. Atmos. Sci., 46, 2757-2782.

Sato, T., T. Yoshikane, M. Sato, H. Miura, and H. Fujinami, 2008: Resolution dependency of the diurnal cycle of convective cloud over the Tibetan Plateau in a mesoscale model. $J$. Meteor. Soc. Japan, 86A, 17-31.

Sellers, P. J., Y. Mintz, Y. C. Sud, and A. Dalcher, 1986: A Simple Biosphere Model ( $\mathrm{SiB})$ for use within general circulation models. J. Atmos. Sci., 43, 505-531.

Seneviratne, S. I., T. Corti, E. L. Davin, M. Hirschi, E. B. Jaeger, I. Lehner, B. Orlowsky, and A. J. Teuling, 2010: Investigating soil moisture-climate interactions in a changing climate: A review. Earth-Science Reviews, 99, 125-161.

Sugimoto, S., and H. G. Takahashi, 2016: Effect of Spatial Resolution and Cumulus Parameterization on Simulated Precipitation over South Asia. SOLA, 12A, 7-12, doi:10.2151/sola. 12A-002.

Takahashi, G. H., T. Yoshikane, M. Hara, K. Takata, and T. Yasunari, 2010: High-resolution modelling of the potential impact of land-surface conditions on regional climate over Indochina associated with the diurnal precipitation cycle. Int. J. Climatol., 30, 2004-2020.

Yabu S., S. Murai, and H. Kitagawa, 2005: Clear sky radiation scheme. Separate Volume of the Annual Report of NPD, 51, 53-64 (in Japanese).

Yatagai, A., K Kamiguchi, O. Arakawa, A. Hamada, N. Yasutomi, and A. Kitoh, 2012: APHRODITE: Constructing a longterm daily gridded precipitation dataset for Asia based on a dense network of rain gauges. Bull. Amer. Meteor. Soc., 93, 1401-1415.

Manuscript received 26 December 2017, accepted 26 February 2018 SOLA: https://www.jstage.jst.go.jp/browse/solal 